\title{
Emotion regulation and academic perceptions in adolescence
}

\section{ABSTRACT}

Although studied extensively in the field of adolescent mental health, the role of emotion regulation (ER) in the academic functioning of adolescents is not well understood. This study examined the role of ER in adolescents' perceptions of themselves and their learning environments. We compared adolescents with high and low levels of ER on perceptions of school achievement and attitudes towards school and their perception of their parents' academic involvement. Students completed surveys about perceptions of their learning and parental involvement, as well as their ER abilities. Results indicated that students with higher emotion dysregulation endorsed more negative self-perceptions of their own academic abilities, had more negative attitudes towards school, and rated their mothers and fathers as more controlling in relation to their learning. These results demonstrate the importance of ER in the academic context, particularly in the home learning environment

\section{KEYWORDS}

Emotion regulation; emotion dysregulation; adolescence; perceptions of learning; selfperceptions; parental involvement

\section{Introduction}

Emotion dysregulation has been linked to negative outcomes such as depression, delinquency, and maladjustment (Bradley 2000; Gross 1998; Morris et al. 2011; Steinberg and Avenevoli 2000). According to Gratz and Roemer (2004), emotion regulation (ER) can be explained as a concept involving: the awareness and understanding of emotions, acceptance of emotions, ability to control impulsive behaviors and behave in accordance with desired goals when experiencing negative emotions, and the ability to use situationally appropriate ER 
strategies flexibly to modulate emotional responses as desired in order to meet individual goals and situational demands (p. 42).

The ability to regulate one's positive and negative emotions, according to one's goals and context, is an important developmental skill that allows children and adolescents to cope with daily challenges. Furthermore, the awareness and understanding of emotions has been shown to contribute to an individual's motivation, interpersonal resources, memory, and learning (Valiente, Swanson, and Eisenberg 2012)

One domain in which ER has just begun to be explored is academic functioning, a context in which adolescents spend a lot of time and face many important challenges. Although test anxiety is the most extensively researched academic emotion, a literature review by Pekrun et al. (2002) revealed that students experience a wide variety of other emotions in school, such as pride, relief, anger, shame, hopelessness, and boredom. For example, a student who has difficulties, understanding, accepting, and controlling his anger would have difficulties dealing with everyday problems in an academic setting. In line with this, research indicates that deficiencies in ER are related to poor academic performance both directly and indirectly in early childhood and adolescence (Graziano, Reavis, Keane, \& Calkins 2007; Gumora and Arsenio 2002; Supplee et al. 2004; Valiente, Swanson, and Eisenberg 2012).

ER is associated with cognitive deficits, specifically executive functioning, which can play a significant role in the academic outcomes in childhood and adolescence. Executive functioning is a set of cognitive skills that provide an individual with the ability to engage in goal-directed behaviours, inhibit one's behaviours, and reduce attention to non-essential stimuli (Calkins and Marcovitch 2010). These executive functioning skills are considered integral to later academic functioning (Calkins and Marcovitch 2010). Although the link between executive 
functioning deficits and ER is well established, the link between ER and academic functioning is not. Research has shown that low ER, a common characteristic in internalising forms of psychopathology such as depression and anxiety, is also involved in predicting poor social functioning (Gross 2002). Additionally, ER can have effects on other aspects of learning, such as peer group learning activities, perceptions and attitudes towards school, or parent-child interactions around learning (Eisenberg et al. 1995).

Given the breadth of research on the gender differences associated with emotionality, it is not surprising that gender differences in ER have been revealed (Brody and Hall 2008; ElseQuest et al. 2006; Hamilton and Jensvold 1992; Hampel and Petermann 2006; Nolen-Hoeksema 1987). Research has found that girls expressed more submissive emotions than boys and were less likely to display disharmonious emotions compared to boys (Chaplin, Cole, and ZahnWaxler 2005). High levels of submissive emotions in females were found to be predictive of future internalising problems, whereas the high levels of disharmonious emotions in males were predictive of externalising problems (Chaplin, Cole, and Zahn-Waxler 2005). A study by Neumann et al. (2010) found sub- stantial gender differences on the Difficulties in Emotion Regulation Scale (DERS; Gratz and Roemer 2004). Female adolescents reported significantly greater emotional non-acceptance, greater emotional awareness, and less access to effective ER strategies than males, leading to lower ER scores (Neumann et al. 2010). Additionally, female adolescents reported lower emotional clarity and greater difficulties controlling impulsive behaviours when distressed (Neumann et al. 2010). With these gender differences in mind, our study examined the role of ER in adolescents' perceptions of themselves and their learning environments. 


\section{Perceptions of academic achievement and attitudes towards school}

A domain implicated in both ER and academic functioning is the adolescents'

perceptions of academic achievement and attitudes towards school. ER is an aspect of individual ontogeny that can impact other parts of the child's life, such as student motivation, cognitive resources, and learning strategies. These characteristics, or lack thereof, can lead to either positive or negative perceptions of academic achievement and attitudes towards school (Pekrun et al. 2002). These perceptions and attitudes have also been associated with psychological and behavioural adjustment, as well as academic achievement (Wang and Holcombe 2010; Way, Reddy, and Rhodes 2007). Students with low ER had more negative attitudes towards school, which uniquely contributed to lower grade point averages in language arts and mathematics (Gumora and Arsenio 2002). It was proposed that these negative attitudes reflected a combination of both parental and school-related influences. In another study, students with low ER had more negative relationships with their teacher, as well as trouble learning in the classroom, completing assignments, and being productive (Grazianos et al. 2007). ER research has also found that males with difficulties are more prone to externalising behaviours, therefore, it is likely that they would have more negative perceptions of their academic achievement and attitudes towards school than females (Grazianos et al. 2007). These findings demonstrate the complexity of the interactions between ER, academic perceptions and attitudes, teacher/parent influence, and academic functioning. For this reason, it is necessary to examine not only these perceptions and attitudes associated with ER but the parental influence as well.

\section{Parental involvement in learning}

Parental involvement in learning is another domain implicated in both ER and academic functioning. Parent-child school-focused interactions play a critical role in the academic 
development of children and are likely associated with an adolescent's own characteristics, such as motivation and temperament (Hoover-Dempsey and Sandler 1995; Ryan \& Adams, 1995). Research has suggested that the type of parental involvement differentially affected the academic outcomes of their child (Fan and Chen 2001; Pomerantz, Moorman, and Litwack 2007). Two types of parenting behaviours, support and control, have emerged in the literature as important contributors to youth's academic success (Grolnick 2003). Parental supportive involvement, such as praise, attentiveness, and reinforcement, enhances academic achievement. On the other hand, controlling involvement, such as punishment, intrusion, or criticism, compromises academic achievement (Pomerantz, Grolnick, and Price 2005). As such, parenting style is critical in determining whether a parent's involvement in their child's learning is beneficial.

The type of parental involvement is also impacted by a child's own characteristics, creating a reciprocal relationship. For instance, studies have demonstrated that temperament and behaviour problems predict more negative parenting behaviours (Dumas and Wekerle 1995; Ge et al. 1996). Because it is well established that ER is strongly associated with social interactions, it is not surprising that a recent review of the literature found support for the notion that a child's emotional and regulatory characteristics (e.g. frustration, fearfulness, and effortful control) can impact type of parental involvement (Kiff, Lengua, and Zalewski 2011). Based on this evidence, it appears that an adolescent's ER ability could be strongly associated with the degree to which parents are supportive and/or controlling parenting in a learning context. As a result, ER deficits may be associated with academic functioning through parental involvement in learning. Adolescents with ER deficits would likely cause more parental stress, which is linked to more controlling parental involvement (Hoover-Dempsey et al. 2005). Because males are more likely to have externalising behaviours, it is also likely that gender would impact parental involvement. 
These gender differences, however, are not well established by past research.

Maternal and paternal differences in parental involvement are also not well established. Studies investigating parental involvement in learning have been based on maternal responses primarily. More recently, researchers have begun addressing this issue and incorporating information from fathers. Studies addressing the influence of father involvement are less common but suggest that fathers also have a positive impact on youth outcomes. For instance, fathers' involvement in their child's schooling has been linked to higher achievement and positive school attitudes (Flouri, Buchanan, and Bream 2002; McBride, Schoppe-Sullivan, and Moon-Ho 2005). Interestingly, fathers' involvement appears to have an influence on children's outcomes above and beyond the impact of mothers (Greif and Greif 2004). Because of this emerging evidence of the differential impact of mothers and fathers on children's developmental outcomes, parental gender was also examined in our study.

\section{Current study}

ER is a critical developmental skill that is associated with successful development in a range of developmental contexts. Although many child characteristics have been found to be associated with academic achievement (e.g. motivation, self-esteem, academic self-competence, and attention deficit hyperactivity disorder (ADHD) symptomology), relatively little work has examined whether ER is also associated with different aspects of academic life in adolescence, such as perceptions of school achievement and attitudes towards school (Eskilson et al. 1986; Grolnick, Ryan, and Deci 1991; Martinez-Pons 1996; Rogers et al. 2009a, 2009b). Additionally, research has found that adolescent characteristics are associated with whether parents engage in more supportive or more controlling involvement in school-related issues, but again, little research to date has examined the relationship between an adolescent's ER and parenting 
behaviours in an academic context (Eskilson et al. 1986; Ginsburg and Bronstein 1993; Grolnick, Ryan, and Deci 1991; Hong and Ho 2005; Koutsoulis and Campbell 2001; Martinez-Pons 1996; Rogers et al. 2009a).

The current study aims to investigate the role of ER in academic perceptions and perceptions of parental involvement in learning among adolescents. By examining all of these variables, the current study will provide a global picture of the role of ER in the academic experience of adolescents at school and at home. Parent gender was included in the study due to emerging evidence that mothers and fathers have differential effects on their children. We expected that children with low levels of ER would both report worse attitudes towards school and lower perceptions of success, and receive less supportive parenting. We did not make specific hypothesis about parent or child gender, due to lack of well-established literature on these variables.

\section{Methods}

\section{Total sample}

Participants in the current study were drawn from a larger pool of participants in Grade 9 $(N=825)$ taking part in a 3-year longitudinal project investigating stress and coping strategies. Participants were recruited from 15 high schools in and around Montreal, Quebec, Canada. Of the total sample, the mean age was 13.37 years, and 362 were boys (mean age 13.41 years) and 463 were girls (mean age 13.34 years). Of these, 768 (92.4\%) spoke English at home, 252 (30.3\%) spoke French at home, and 108 (13.0\%) spoke another language at home. The vast majority indicated Canada (95.3\%) as their country of birth, followed others (3.5\%), and finally by United States $(1.2 \%)$. 


\section{Measures}

\section{Emotion regulation}

We used the DERS (Gratz and Roemer 2004) to assess ER abilities. The DERS is a 36item self-report measure designed to assess clinically relevant difficulties in ER. This scale yields a Total Emotion Regulation Scale, with higher scores indicating more dysregulation. It consists of 36 items that are scored on a five-point Likert scale, ranging from 1 (almost never) to 5 (almost always). Psychometric research demonstrates that the DERS scores have good test-retest reliability ( $\alpha=.93$; Gratz and Roemer 2004), and the Total DERS score has been found to have high internal consistency within both clinical (e.g. Fox et al. 2007; Gratz et al. 2008) and nonclinical populations (e.g. Gratz and Roemer 2004; Johnson et al. 2008).

In order to compare children with high and low levels of ER, we dichotomised the sample variable into 'high' and 'low' scores based on quartile cutoffs that were calculated separately for boys and girls. Because of the scoring system for the DERS, a 'high' score corresponds to lower ER abilities. Thus, in the remainder of the paper, this dichotomised variable will be labelled as 'high ER ability' and 'low ER ability', which correspond to participants in the top quartile and bottom quartile, respectively. These cutoffs were generated separately for boys and girls due to preliminary analysis that indicated significant differences in DERS scores for boys and girls.

\section{Academic perceptions}

Participating students completed the Questionnaire d'évaluation du décrochage en milieu scolaire: English version (DEMS; Potvin et al. 2003) to assess academic perceptions. The DEMS is a self-report questionnaire that assesses the risk of high school dropout. For the purpose of this study, the Attitudes towards School and Perceptions of School Achievement subscales were used to evaluate academic perceptions. This inventory was originally validated using a sample of high 
school students in regions of Quebec and was translated for use in this study. The DEMS has been shown to have good reliability and validity (Potvin et al. 2004). The internal reliability of the subscales ranged from acceptable to very good ( $\alpha=.59$ to .83$)$, and test-retest reliability was very good, with correlation coefficients ranging from .72 to .88 .

\section{Parental involvement}

The Parental Support for Learning Scale (PSLS: Rogers et al. 2013) separately assesses students' perceptions of their mothers' and fathers' educational involvement in the home. The original version of this scale was used to assess elementary school aged children's perceptions; however a modified version of the scale has recently been developed to be more relevant for parental involvement in the adolescent years (Rogers et al. 2013). The adolescent version consists of two subscales: Controlling Parental Involvement and Supportive Parental Involvement. Previous work using this scale on elementary school aged children suggests that it possesses acceptable psychometric properties (Rogers et al. 2013). Examples of items on the Controlling Parental Involvement subscale include 'This parent tries to tell me how to approach my schoolwork', 'This parent insists I do my schoolwork his/her way', and 'When I get a poor grade, I feel the need to hide it from this parent'. Examples of items on the Supportive Involvement subscale include 'This parent is typically happy to talk to me about my learning', 'When I am struggling at school, this parent listens to my opinion and perspective', and 'This parent allows me to make my own decisions about my school-work'. These items are rated on a 1-5 likert scale with 1 representing 'Strongly Disagree or Never' and 5 representing 'Strongly Agree or Always'. The internal reliability of the subscales ranged from acceptable to good on the mother scale ( $\alpha=.60$ to .82 ) and acceptable to good on the father scale ( $\alpha=.71$ to .89 ). 


\section{Procedure}

Participants for this study were recruited as part of larger longitudinal project on coping with stress in the transition to high school. Students brought home a parental consent form detailing the main research purposes and procedure. Of the students who returned consent forms, $825(67 \%)$ agreed to participate. For this study, data were collected during the second year of the study, thus, the variables used in this study were measured in 1 year. Participants completed questionnaires during two 45-minute sessions. Participants at each school were brought to a common area in the school (e.g. cafeteria) in groups of range from 20 to 50 and were presented with an envelope that contained a student assent form and questionnaires. Instructions were read aloud by a research assistant, and participants responded individually. Students sat apart from each other and trifold screens were used to ensure more confidentiality in responses.

\section{Results}

\section{Statistical analysis}

To examine the impact of ER ability on academic perception variables, multivariate analysis of variance (MANOVA) was used to compare children with high and low levels of ER abilities on perceptions of success and attitudes towards school, as well as perceptions of parental involvement in learning (maternal support, maternal control, paternal support, paternal control). Because girls showed higher levels of ER (mean $=73.9(23.4), t=-2.99, p<.01)$ than boys $($ mean $=69.4(18.8))$, gender was included as an independent variable.

\section{Descriptive statistics}

In our three variables of interest, there was $19-25 \%$ missing data at random. Little's missing completely at random (MCAR) test proved significant $\left(\chi^{2}=185.91, p=.000, \mathrm{DF}=113\right)$, however separate variance t-tests indicated that the data were not missing in a pattern related to 
the dependent variable (DV;ts> .05). As such, missing data were removed listwise in all analyses, leaving a sample size of 387. Because we were interested in the role of low ER levels, we divided participants into two ER groups: high and low ER levels. Similar to previous studies, gender differences were present in the levels of ER. For this reason, we formed the ER groups from the lowest and highest quartile of ER scores for boys and girls separately (Boys: $<56=$ High ER, $n=86,>80=$ Low ER, $n=92$; Girls: $<58=$ High ER, $n=120,>88=$ Low ER, $n=$ 113). An independent sample's t-test was run comparing the ages of children in the high and low ER group, and a $\chi 2$ tests were performed between the two groups (high and low ER), and no significant differences were found in age or language (both $p>.05$ ).

\section{Gender and ER factors with academic perception variables}

A 2 (gender) $\times 2$ (ER level) MANOVA was performed on two academic perception variables: Perceptions of school success and Attitudes towards school. The results are presented in $\underline{\text { Table 1. }}$. There was a significant multivariate effect for ER level (Wilk's $\Lambda=.242, F(2,306)=$ $48.765, p<.001, \eta^{2}=0.242$ ), such that participants in the high ER ability group scored lower on both academic perception variables, indicative of more positive academic functioning, than those in the low ER ability group. There was no significant main effect of gender (Wilks's $\Lambda=0.992$, $\left.F(2,306)=1.282, p>.1, \eta^{2}=0.008\right)$ or any interactions (Wilks's $\Lambda=0.992, F(2,306)=1.177$, $p>.1, \eta^{2}=0.008$ ), thus gender was not included in the table.

\section{Gender and ER factors with parental involvement variables}

A 2 (gender) $\times 2$ (ER level) MANOVA was performed on each of the four PSLS subscales (maternal support, maternal control, paternal support, paternal control). The results are presented in $\underline{\text { Table 2. }}$. There was a significant main effect for ER level (Wilks's $\Lambda=.608, F(4$, $\left.251)=40.445, p<.001, \eta^{2}=0.392\right)$ and gender (Wilks's $\Lambda=.950, F(4,251)=3.335, p<.05, \eta^{2}$ 
$=0.05$ ), such that participants in the low ER ability group perceived both their mothers and their fathers as more controlling, and boys perceived both their mothers and fathers as more controlling than girls did. There were no significant interactions between ER and gender (Wilks's $\left.\Lambda=0.984, F(2,306)=1.048, p>.1, \eta^{2}=0.016\right)$.

\section{Discussion}

The findings from this study build upon previous ER research by illustrating the adverse effects of dysregulation in the educational context for young adolescents. The results indicate that ER, in this developmental period, is associated with two variables that are related to academic functioning: academic perceptions and parental involvement in learning. In support of our hypotheses, results indicated that compared to adolescents with high ER abilities, those with low ER reported lower perceptions of school success and attitudes towards school, both of which are important indicators of negative academic outcomes. Moreover, participants in the low ER group rated their parents as more controlling in their school-related involvement, suggesting that adolescents with lower ER skills report negative parenting strategies in their academic endeavours. Previous research has identified many different child characteristics that are involved in the relationship between academic perceptions and parent involvement style, such as motivation, temperament, self-concept, academic self-competence and ADHD symptomology (e.g. Hamachek 1995; Hoover-Dempsey and Sandler 1995; Kiff, Lengua, and Zalewski 2011; Ryan and Adams 1995; Stinnett, Oehler-Stinnett, and Stout 1991; Van Den Bergh 2006). The present study extends these findings by establishing the association between ER, adolescents' academic perceptions and attitudes, and their perceptions of parental involvement in learning. Thus, these results add to the limited research on the association between ER and academic achievement variables in this developmental period and confirm its importance in the academic 
context. Borrowing from studies of younger children, researchers have proposed different ways in which ER may be related to academic functioning. For instance, Blair (2002) suggests that inefficient ER physiologically inhibits a child's use of higher order cognitive processes, such as attention, thus inhibiting the ability to manage and tolerate academically challenging tasks. Others have suggested that ER may contribute to learning outcomes by affecting behavioural control in the classroom (Masten et al. 2005). The findings from the current study support this literature, demonstrating that emotion dysregulation is negatively associated with academic attitudes and perceptions about school. An additional possibility, as suggested by this study, is that ER skills are related to academic success and subsequently may affect the quality of important learning-related interactions with parents, such as those related to academic performance, grades, report cards, motivation, work ethic, and goals. Logistic regression would be required to investigate this hypothesis further.

While many conceptualise ER as a process that occurs within the individual, the interpersonal nature of ER has been well established using studies of parent-child dyads (Collins 1990). Despite this substantial body of literature, this study is the first to examine the association between ER and parental involvement perceptions in the context of learning. The current study suggests that adolescents' emotion regulatory skills may play an important part in these learningrelated inter- actions in the home. Interestingly, the observed association between emotion dysregulation and parental control was not observed for parental support. Thus, high and low ER levels were related to differences in controlling parenting but not supportive parenting. This may be explained by impaired social interactions during learning-related interactions (e.g. during homework time) caused by an adolescent's emotion dysregulation. Some research has demonstrated that low ER predicts poor social functioning, which is a problem likely to arise 
during challenging homework periods and may elicit negative parenting strategies without necessarily affecting the level of supportive parenting used (Eisenberg et al. 1995),. We observed a main effect of child gender on parent involvement style $\left(\eta^{2}=0.05\right)$. Specifically, we found a small effect indicating that boys rated both their mothers $\left(\eta^{2}=0.039\right)$ and fathers $\left(\eta^{2}\right.$ $=0.039)$ as more controlling than girls did, which was not true for maternal $\left(\eta^{2}=0.003\right)$ or paternal $\left(\eta^{2}=0.001\right)$ support. Specifically, this suggests that boys may perceive more controlling parenting than girls do, a finding that replicates past studies documenting that boys receive less favourable parenting than girls do in general (Brand et al. 2011; Beyers and Goossens 2008; Carter and Wojtkiewicz 2000) and extends this finding into parent involvement in learning specifically. However, the effect size for this finding was minimal $\left(\eta^{2}=0.05\right.$ overall), suggesting that any effects of gender on parental involvement are minimal compared to that of ER abilities. While we suspected that there would be differences in the association between ER and parental involvement based on parent gender, we did not find any such effects. Adolescents in the low ER group rated both their mothers and fathers as more controlling in their involvement, while maternal and paternal supportive involvement was not significantly different based on ER ability. In both of these findings, effect sizes were similar for mothers and fathers. This is surprising given previous research, which although limited, does suggest that fathers can have an influence on adolescents above and beyond mothers (Greif and Greif 2004). For instance, fathers' academic involvement is often associated with increased levels of academic achievement (McBride, Schoppe- Sullivan, and Moon-Ho 2005) and more positive school attitudes (Flouri, Buchanan, and Bream 2002). This finding demonstrates the discrepancy in the literature regarding differential effects for maternal and paternal parenting involvement effects and highlights the need for more research. 
Despite providing a global picture of the relationships between ER, academic perceptions, and perceptions of the parental involvement, the current study does not provide evidence of causality, and thus, no conclusions can be drawn from this study regarding the direction of the results. Therefore, it is possible that both the academic and parental variables are influencing ER. Moreover, research has suggested several factors that may play a significant role in both academic percep- tions and perceptions of parental involvement in learning. Garnefski (2000) found that adolescents who had negative perceptions of their families and school often experienced depressive symptoms and engaged in antisocial behaviours. Because of the relationship between ER and mental health, future research should control for mental illness to clarify the results of the present study. It would also be helpful to measure parental emotional regulation, as this may be associated with the child's own ER, perceptions of their various environments, including school, and their perceptions of parental involvement in learning. Peer and teacher relationships are also implicated in academic perceptions, particularly in adolescence as they are important in this developmental stage (Way, Reddy, and Rhodes 2007). Negative relationships with both their peers and teachers, as well as poor academic achievement, may translate into negative perceptions of school. For this reason, it would be useful to assess teacher and peer support, as well as their academic achievement in future research. In future research, these potential confounding variables should be examined as a means of understanding the role of ER above and beyond the results of this study. We hypothesise that ER would directly affect the factors discussed above, and thus, indirectly affect the variables examined in the current study. 


\section{Conclusions and implications}

The broad goal of this study was to contribute to our understanding of the role of ER, academic perceptions and attitudes, and parental involvement in learning, in adolescence. During the years of adolescence, children undergo dramatic changes across all areas of development; they begin to play a more active role in initiating and controlling family interactions, and begin to seek more independence and autonomy from their parents (Granic et al. 2003). It is also the time during which most children transition to high school, a critical juncture in which the structure and demands of school and relationships with parents change considerably. Importantly, adolescents who do not manage this transition well have a substantially increased chance of not completing high school. This study suggests that emotion dysregulation may be a key risk factor in poor academic functioning, as it is associated with important academic variables such as perceptions of academic achievement, attitudes towards school, and parental involvement in learning. From a clinical perspective, these results provide further evidence of the need for clinicians to consider ER ability as a regular part of case conceptualisation, treatment planning, and prognosis of adolescent clients, particularly when considering academic difficulties. Additionally, given the link between adolescent ER and controlling parental involvement in homework, psycho-education components of parenting interventions ought to more regularly include concepts of ER. Taken together, these results can be used by clinicians and researchers alike to better inform their future research questions and clinical practice with families and children.

\section{Limitations}

Although the current study has provided important insights regarding the relationship between ER, academic variables, and perceptions of parental involvement in learning, there are 
several limitations that should be considered before drawing conclusions. A key limitation was the lack of control variables. As mentioned previously, psychological and behavioural adjustment are important contributors to perceptions and attitudes towards school, and thus, future research should include these variables in order to cement the role of ER in these relationships (Wang and Holcombe 2010; Way, Reddy, and Rhodes 2007). The cross-sectional, correlational nature of the study was another limitation which inhibited our ability to make causal inferences. Although we found significant associations, we are not able to determine the direction of these associations. A longitudinal study with multiple time points, examining a variety of potentially confounding variables, could provide evidence of a cause and effect relationship. This study also relied on self-report measures from students as a means of assessing both the academic variables and the parental involvement. It would be advantageous in future studies to include multiple sources of information, such as parents and teachers. Finally, our data set was limited as there was a considerable amount of missing data. Although MCAR test was significant, list-wise deletion reduced the sample size significantly. 


\section{References}

Beyers, W., and L. Goossens. 2008. "Dynamics of Perceived Parenting and Identity Formation in Late Adolescence." Journal of Adolescence 31 (2): 165-184. doi:10.1016/j.adolescence.2007.04.003.

Blair, C. 2002. "School Readiness: Integrating Cognition and Emotion in a Neurobiological Conceptualization of Children's Functioning at School Entry.” American Psychologist 57 (2): 111-127. doi:10.1037/0003-066X.57.2.111.

Bradley, S. J. 2000. Affect Regulation and the Development of Psychopathology. New York, NY: Guilford Press.

Brand, S., M. Gerber, J. Beck, N. Kalak, M. Hatzinger, U. Pühse, and E. Holsboer-Trachsler. 2011. "Perceived Parenting Styles Differ between Genders but Not between Elite Athletes and Controls." Adolescent Health, Medicine, and Therapeutics 2: 9-14. doi:10.2147/AHMT.

Brody, L. R., and J. A. Hall. 2008. "Gender and Emotion in Context.” Handbook of Emotions 3: $395-408$.

Calkins, S. D., and S. Marcovitch. 2010. Emotion regulation and executive functioning in early development: Integrated mechanisms of control supporting adaptive functioning.

Carter, R. S., and R. A. Wojtkiewicz. 2000. "Parental Involvement with Adolescents' Education: Do Daughters or Sons Get More Help?” Adolescence 35 (137): 29-44.

Chaplin, T. M., P. M. Cole, and C. Zahn-Waxler. 2005. "Parental Socialization of Emotion Expression: Gender Differences and Relations to Child Adjustment.” Emotion 5 (1): 8088. doi:10.1037/1528-3542.5.1.80.

Collins, W. A. 1990. "Parent-Child Relationships in the Transition to Adolescence: Continuity 
and Change in Interaction, Affect, and Cognition.” In From Childhood to Adolescence: A Transitional Period? edited by R. Montemayor, G. R. Adams, and T. P. Gullotta, 85-106. Vol. 2. London: Sage.

Dumas, J. E., and C. Wekerle. 1995. "Maternal Reports of Child Behavior Problems and Personal Distress as Predictors of Dysfunctional Parenting." Development and Psychopathology 7: 465-479. doi:10.1017/S0954579400006635.

Eisenberg, N., R. A. Fabes, B. Murphy, P. Maszk, M. Smith, and M. Karbon. 1995. "The Role of Negative Emotionality and Regulation in Children's Social Functioning: A Longitudinal Study." Child Development 66 (5): 1360-1384. doi:10.2307/1131652.

Else-Quest, N. M., J. S. Hyde, H. H. Goldsmith, and C. A. Van Hulle. 2006. "Gender Differences in Temperament: A Meta-Analysis.” Psychological Bulletin 132 (1): 33-72. doi:10.1037/0033-2909.132.1.33.

Eskilson, A., M. G. Wiley, G. Muehlbauer, and L. Dodder. 1986. "Parental Pressure, SelfEsteem, and Adolescent Reported Deviance: Bending the Twig Too Far.” Adolescence 21: 501-515.

Fan, X., and M. Chen. 2001. "Parental Involvement and Students' Achievement: A MetaAnalysis.” Educational Psychology Review 13: 1-22. doi:10.1023/A:1009048817385.

Flouri, E., A. Buchanan, and V. Bream. 2002. “Adolescents' Perceptions of Their Fathers' Involvement: Significance to School Attitudes.” Psychology in the Schools 39: 575-582. doi:10.1002/(ISSN)1520-6807.

Fox, H. C., S. R. Axelrod, P. Paliwal, J. Sleeper, and R. Sinha. 2007. "Difficulties In Emotion Regulation And Impulse Control During Cocaine Abstinence.” Drug And Alcohol Dependence 89 (2-3): 298-301. doi:10.1016/j. drugalcdep.2006.12.026. 
Garnefski, N. 2000. “Age Differences in Depressive Symptoms, Antisocial Behavior, and Negative Perceptions of Family, School, and Peers among Adolescents.” Journal of the American Academy of Child \& Adolescent Psychiatry 39 (9): 1175-1181. doi:10.1097/00004583-200009000-00018.

Ge, X., R. Conger, R. Cadoret, J. Neiderhiser, W. Yates, E. Troughton, and M. A. Stewart. 1996. “The Developmental Interface between Nature and Nurture: A Mutual Influence Model of Child Antisocial Behavior and Parent Behavior.” Developmental Psychology 32: 574589. doi: $10.1037 / 0012-1649.32 .4 .574$.

Ginsburg, G. S., and P. Bronstein. 1993. "Family Factors Related to Children's Intrinsic/Extrinsic Motivational Orientation and Academic Performance.” Child Development 64: 1461-1474. doi:10.2307/1131546.

Granic, I., T. Hollenstein, T. J. Dishion, and G. R. Patterson. 2003. "Longitudinal Analysis of Flexibility and Reorganization in Early Adolescence: A Dynamic Systems Study of Family Interactions.” Developmental Psychology 39: 606-617. doi:10.1037/0012$\underline{1649.39 .3 .606 .}$

Gratz, K. L., and L. Roemer. 2004. "Multidimensional Assessment of Emotion Regulation and Dysregulation: Development, Factor Structure, and Initial Validation of the Difficulties in Emotion Regulation Scale.” Journal of Psychopathology and Behavioral Assessment 26 (1): 41-54. doi:10.1023/B:JOBA.0000007455.08539.94.

Gratz, K. L., M. T. Tull, D. E. Baruch, and M. A. Bornovalova. 2008. "Factors Associated With Co-occurring Borderline Personality Disorder Among Inner-city Substance Users: The Roles Of Childhood Maltreatment, Negative Affect Intensity/reactivity, And Emotion Dysregulation." Comprehensive Psychiatry 49 (6): 603-615. 
Grazianos, P. A., R. D. Reavis, S. P. Keane, and S. D. Calkins. 2007. "The Role of Emotion Regulation in Children's Early Academic Success.” Journal of School Psychology 45 (1): 3-19. doi:10.1016/j.jsp.2006.09.002.

Greif, J. L., and G. L. Greif. 2004. "Including Fathers in School Psychology Literature: A Review of Four School Psychology Journals.” Psychology in the Schools 41: 575-580. doi:10.1002/(ISSN)1520-6807.

Grolnick, W. S. 2003. The Psychology of Parental Control: How Well-Meant Parenting Backfires. Mahwah, NJ: Lawrence Erlbaum Associates Publishers.

Grolnick, W. S., R. M. Ryan, and E. L. Deci. 1991. “The Inner Resources for School Achievement: Motivational Mediators of Children's Perceptions of Their Parents." Journal of Educational Psychology 83: 508-517. doi:10.1037/0022- 0663.83.4.508.

Gross, J. J. 1998. “The Emerging Field of Emotion Regulation: An Integrative Review.” Review of General Psychology 2: 271-299. doi:10.1037/1089-2680.2.3.271.

Gross, J. J. 2002. "Emotion Regulation: Affective, Cognitive, and Social Consequences." Psychophysiology 39: 281-291. doi:10.1017/S0048577201393198.

Gumora, G., and W. Arsenio. 2002. "Emotionality, Emotion Regulation, and School Performance in Middle School Children.” Journal of School Psychology 40 (5): 395-413. doi: $10.1016 / \mathrm{S} 0022-4405(02) 00108-5$.

Hamachek, D. 1995. "Self-Concept and School Achievement: Interaction Dynamics and a Tool for Assessingthe Self- Concept Component.” Journal of Counseling \& Development 73: 419-425. doi:10.1002/j.1556-6676.1995.tb01775.x.

Hamilton, J. A., and M. Jensvold. 1992. "Personality, Psychopathology, and Depressions in Women.” In Personality and Psychopathology: Feminist Reappraisals, edited by Laura S. 
Brown and Mary Ballou, 116-143. New York: Guilford Press.

Hampel, P., and F. Petermann. 2006. "Perceived Stress, Coping, and Adjustment in Adolescents." Journal of Adolescent Health 38 (4): 409-415. doi:10.1016/j.jadohealth.2005.02.014.

Hong, S., and H.-Z. Ho. 2005. "Direct and Indirect Longitudinal Effects of Parental Involvement on Student Achievement: Second-Order Latent Growth Modeling across Ethnic Groups.” Journal of Educational Psychology 97: 32-42. doi:10.1037/0022-0663.97.1.32.

Hoover-Dempsey, K. V., and H. M. Sandler. 1995. "Parental Involvement in Children's Education: Why Does It Make a Difference?” Teachers College Record 97: 310-331.

Hoover-Dempsey, K. V., J. M. Walker, H. M. Sandler, D. Whetsel, C. L. Green, A. S. Wilkins, and K. Closson. 2005. "Why Do Parents Become Involved? Research Findings and Implications.” The Elementary School Journal 106 (2): 105-130. doi:10.1086/499194.

Johnson, K. A., M. J. Zvolensky, E. C. Marshall, A. Gonzalez, K. Abrams, and A. A. Vujanovic. 2008. "Linkages Between Cigarette Smoking Outcome Expectancies And Negative Emotional Vulnerability.” Addictive Behaviors 33 (11): 1416- 1424. doi: 10.1016/j.addbeh.2008.05.001.

Kiff, C. J., L. J. Lengua, and M. Zalewski. 2011. "Nature and Nurturing: Parenting in the Context of Child Temperament."Clinical Child and Family Psychology Review 14 (3): 251-301. doi:10.1007/s10567-011-0093-4.

Koutsoulis, M. K., and J. R. Campbell. 2001. "Family Processes Affect Students' Motivation, and Science and Math Achievement in Cypriot High Schools." Structural Equation Modeling: A Multidisciplinary Journal 8: 108-127. doi:10.1207/S15328007SEM0801_6.

Martinez-Pons, M. 1996. "Test of a Model of Parental Inducement of Academic Self- 
Regulation.” The Journal of Experimental Education 64: 213-227. doi:10.1080/00220973.1996.9943804.

Masten, A., G. Roisman, J. Long, K. Burt, J. Obradović, J. Riley, K. Boelcke-Stennes, and A. Tellegen. 2005. "Developmental Cascades: Linking Academic Achievement and Externalizing and Internalizing Symptoms over 20 Years.” Developmental Psychology 41: 733-746. doi:10.1037/0012-1649.41.5.733.

McBride, B. A., S. J. Schoppe-Sullivan, and H. Moon-Ho. 2005. "The Mediating Role of Fathers' School Involvement on Student Achievement.” Journal of Applied Developmental Psychology 26: 201-216. doi:10.1016/j. appdev.2004.12.007.

Morris, A. S., J. S. Silk, M. D. S. Morris, L. Steinberg, K. J. Aucoin, and A. W. Keyes. 2011. "The Influence of Mother-Child

Emotion Regulation Strategies on Children's Expression of Anger and Sadness." Developmental Psychology 47 (1): 213-225. doi:10.1037/a0021021.

Neumann, A., P. A. C. Van Lier, K. L. Gratz, and H. M. Koot. 2010. "Multidimensional Assessment of Emotion Regulation Difficulties in Adolescents Using the Difficulties in Emotion Regulation Scale.” Assessment 17: 138-149. doi:10.1177/ 1073191109349579.

Nolen-Hoeksema, S. 1987. "Sex Differences in Unipolar Depression: Evidence and Theory." Psychological Bulletin 101 (2): 259-282. doi:10.1037/0033-2909.101.2.259.

Pekrun, R., T. Goetz, W. Titz, and R. Perry. 2002. “Academic Emotions in Students' SelfRegulated Learning and Achievement: A Program of Qualitative and Quantitative Research.” Educational Psychologist 37 (2): 91-105. doi:10.1207/S15326985EP3702_4. Pomerantz, E. M., W. S. Grolnick, and C. E. Price. 2005. The Role of Parents in How Children Approach Achievement: A Dynamic Process Perspective. New York, NY: Guilford 
Publications.

Pomerantz, E. M., E. A. Moorman, and S. D. Litwack. 2007. "The How, Whom, and Why of Parents' Involvement in Children's Academic Lives: More is Not Always Better.” Review of Educational Research 77: 373-410. doi:10.3102/ 003465430305567.

Potvin, P., A. Côté-Doré, L. Fortin, E. Royer, D. Marcotte, and D. Leclerc. 2003. Questionnaire d'identification des élèves à risque de décrochage scolaire. Université du Québec, Trois-

Rivières (Québec). Ce questionnaire est maintenant publié aux Éditions du CETREQ, Québec, 2007.

Potvin, P., L. Fortin, D. Marcotte, E. Royer, and R. Deslandes. 2004. Guide De Prévention Du Décrochage Scolaire. Loretteville: Centre de transfert pour la réussite éducative au Québec.

Rogers, M., C. Markel, J. Midgett, B. Ryan, and R. Tannock. 2013. “Measuring Children's Perceptions of Parental Involvement in Conjoint Behavioral Consultation: Factor Structure and Reliability of the Parental Support for Learning Scale.” Assessment for Effective Intervention39 (3): 170-181.

Rogers, M. A., J. Theule, B. Ryan, G. Adams, and L. Keating. 2009a. "Parental Involvement and Children's School Achievement: Evidence for Mediating Processes.” Canadian Journal of School Psychology 24: 34-57. doi:10.1177/ 0829573508328445.

Rogers, M. A., J. Wiener, I. Marton, and R. Tannock. 2009b. "Supportive and Controlling Parental Involvement as Predictors of Children's Academic Achievement: Relations to Children's ADHD Symptoms and Parenting Stress.” School Mental Health 1: 89-102.

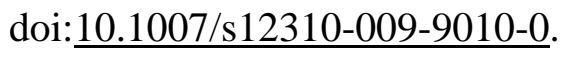

Ryan, B. A., and G. R. Adams. 1995. “The Family-School Relationships Model.” In The 
Family-School Connection: Theory, Research, and Practice, edited by B. Ryan, et al. 328. Thousand Oaks, CA: Sage.

Steinberg, L., and S. Avenevoli. 2000. "The Role of Context in the Development of

Psychopathology: A Conceptual Framework and Some Speculative Propositions." Child Development 71: 66-74. doi:10.1111/cdev.2000.71.issue-1.

Stinnett, T. A., J. O. Oehler-Stinnett, and L. J. Stout. 1991. "Development of the Teacher Rating of Academic Achievement Motivation: TRAAM.” School Psychology Review 4: 609622.

Supplee, L., D. S. Shaw, K. Hailstones, and K. Hartman. 2004. "Family and Child Influences on Early Academic and Emotion Regulatory Behaviors.” Journal of School Psychology 42: 221-242. doi:10.1016/j.jsp.2004.02.001.

Valiente, C., J. Swanson, and N. Eisenberg. 2012. "Linking Students' Emotions and Academic Achievement: When and Why Emotions Matter." Child Development Perspectives 6 (2): 129-135. doi:10.1111/cdep.2012.6.issue-2.

Van Den Bergh, B. R. 2006. “Influences of Distal and Proximal Family Environment Variables on Preadolescents' Self- Concept.” In The Concept of Self in Education, Family and Sports, edited by A. P. Prescott, 153-177. Hauppauge, NY: Nova Science Publishers. Wang, M.-T., and R. Holcombe. 2010. “Adolescents' Perceptions of School Environment, Engagement, and Academic Achievement in Middle School.” American Educational Research Journal 47 (3): 633-662. doi:10.3102/ 0002831209361209.

Way, N., R. Reddy, and J. Rhodes. 2007. "Students' Perceptions of School Climate during the Middle School Years: Associations with Trajectories of Psychological and Behavioral Adjustment.” American Journal of Community Psychology 40 (3-4): 194-213. 
doi:10.1007/s10464-007-9143-y. 
This is an Accepted Manuscript of an article published by Taylor \& Francis in 'Emotional and Behavioural Difficulties' on 2017-02-28, available online: https://www.tandfonline.com/10.1080/13632752.2017.1290896.

\section{Tables and Figures}

Table 1. Multivariate analysis on academic perception variables by DERS.

\begin{tabular}{|c|c|c|c|c|c|c|}
\hline & \multicolumn{2}{|c|}{ HighER } & \multicolumn{2}{|c|}{ Low ER } & \multicolumn{2}{|c|}{ MANOVA } \\
\hline & Mean & SD & Mean & SD & $F(1251)$ & $\eta 2$ \\
\hline Perceptions of school success & 24.05 & 5.86 & 20.101 & 4.28 & $78.175 * *$ & .203 \\
\hline Attitudes towards school & 16.46 & 4.173 & 12.32 & 3.098 & $73.325 * *$ & .193 \\
\hline
\end{tabular}

Table 2. Multivariate analysis on parental involvement variables by DERS and gender.

\begin{tabular}{|c|c|c|c|c|c|c|c|c|}
\hline & $\begin{array}{l}\text { High ER } \\
M(\mathrm{SD})\end{array}$ & $\begin{array}{l}\text { Low ER } \\
M \text { (SD) }\end{array}$ & $\begin{array}{l}\text { MANOVA } \\
F(1251)\end{array}$ & $\eta 2$ & $\begin{array}{c}\text { Boys } \\
M(\mathrm{SD})\end{array}$ & $\begin{array}{c}\text { Girls } \\
M(\mathrm{SD})\end{array}$ & $F(1251)$ & $\eta 2$ \\
\hline Mother controlling & $2.93(.7)$ & $1.94(.7)$ & $89.08 * *$ & .260 & $2.6(1.0)$ & $2.2(.92)$ & $10.39 * *$ & .039 \\
\hline Mother supportive & $3.75(.9)$ & $4.44(.5)$ & $56.77 * *$ & .183 & $4.1(.83)$ & $4.2(.77)$ & .729 & .003 \\
\hline Father controlling & $2.96(1.0)$ & $1.89(.7)$ & $101.99^{* *}$ & .286 & $2.6(1.1)$ & $2.2(.92)$ & $10.291 * *$ & .039 \\
\hline Father supportive & $3.55(1.0)$ & $4.39(.6)$ & $71.86^{* *}$ & .221 & $3.9(.87)$ & $4.0(.92)$ & .284 & .001 \\
\hline
\end{tabular}

$* * p<.001$. 
